\title{
ENVIRONMENTAL EFFECTS ON THE DYNAMIC CHARACTERISTICS OF A HISTORIC CATHEDRAL
}

\author{
Carmelo Gentile ${ }^{1}$, and Antonello Ruccolo ${ }^{2}$ \\ ${ }^{1}$ Politecnico di Milano, Department of Architecture, Built environment and Construction engineering \\ Piazza Leonardo da Vinci, 32 - 20133 Milan, Italy \\ e-mail: carmelo.gentile@polimi.it \\ ${ }^{2}$ Politecnico di Milano, Department of Architecture, Built environment and Construction engineering \\ Piazza Leonardo da Vinci, 32 - 20133 Milan, Italy \\ antonello.ruccolo@polimi.it
}

Keywords: Automated modal identification, Cathedral of Milan, Condition-based maintenance, Continuous monitoring, Temperature

\begin{abstract}
The maintenance and preservation of the Milan Cathedral is traditionally performed through well-established and time-scheduled programs of visual inspection and architectural restoration of surfaces, decorations, and statues in Candoglia marble. On the other hand, the structural condition assessment and preservation turns out to be $a$ challenging task due to the dimensions and complexity of the building, the usual uncertainties on the material properties and also the difficulty in inspecting several structural elements. Therefore, a structural monitoring system was recently designed and installed in the Milan Cathedral to assist the condition-based structural maintenance of the monument. The monitoring system includes different sensing technologies to allow appropriate tracking of different long-term structural behavior. The dynamic monitoring of the horizontal response of selected piers is complemented by the static monitoring of the tilt of the same piers and of the strain in selected tie-rods. In addition, the indoor and outdoor environmental parameters are extensively measured as well.

After a concise historic background on the historic monument and the description of the dynamic monitoring system installed in the Milan Cathedral, the paper focuses on the dynamic characteristics of the monument, that were identified in the first hours of continuous monitoring, Subsequently, the results of the first year of dynamic monitoring are presented and discussed, with special attention being given to the influence of environmental parameters on the variations observed in the resonant frequencies and mode shapes. In more details, the presented results highlight that: (a) 8 global vibration modes are automatically detected in the frequency range 1.0-5.0 Hz; (b) the variations observed in the resonant frequencies are mainly driven by temperature, with the effect of thermal changes being very peculiar; (c) the mode shapes and the related mode complexity do not exhibit appreciable fluctuations associated to the environmental changes, so that an appropriate strategy of SHM should be based also on the time invariance of those parameters.
\end{abstract}




\section{INTRODUCTION}

The Milan Cathedral is a world-wide known Heritage monument, whose structural construction took more than 4 centuries, from the apse erection in 1386 until the façade finalization in 1813 [1]. Subsequently, the architectural works continued until the installation of the last iron gate in 1965 and this year is usually indicated as the official completion of the building works. Since 1387 all operational aspects related to the construction, maintenance and restoration of the cathedral are managed by the historic Institution named Veneranda Fabbrica del Duomo di Milano [2] and denoted as Fabbrica in the following. After the construction of the main structures of the cathedral, the Fabbrica main mission moved to continuous inspection, maintenance and preservation of the monument, with those activities being especially related to surfaces, decorations and statues in Candoglia marble.

After the recent assessment of the state of preservation and the tensile force of the metallic tie-rods of the Milan Cathedral [3], the idea of adopting a Structural Health Monitoring (SHM) strategy has been taking shape to continuously assist the structural condition assessment and preservation of the monument. Consequently, a joint research started between the Fabbrica and Politecnico di Milano and a structural monitoring system [4] was designed and installed in the cathedral, with the objectives of providing the information needed for the conditionbased structural maintenance and the creation of a large archive of experimental data useful to enhance the knowledge of the monument.

The long-term monitoring system [4], fully computer based and with efficient transmission of the collected data, includes static and dynamic measurements. The dynamic monitoring is performed through seismometers (electro-dynamic velocity sensors) installed at the top of 14 selected piers and at 3 levels of the main spire. The static monitoring system consists of: (a) bi-axial tilt-meters installed at the top of selected piers and at 3 levels of the main spire; (b) vibrating wire extensometers mounted on the tie-rods exhibiting tensile stress larger than 100 $\mathrm{MPa}$ [3]. Since both the long-term static behavior and the time evolution of dynamic signatures are expected to be sensitive also to environmental changes [5] and especially the temperature might affect the variation of structural parameters in masonry structures [6-11], the indoor and outdoor environmental parameters (temperature and humidity) are extensively measured to establishing correlations with the changes of structural parameters [4-11] and evaluating the risks for the preservation of the main artifacts present in the cathedral [12].

The present paper is mainly aimed at describing the monitoring system installed in the cathedral with emphasis on the dynamic measurements, the processing of the continuously collected time series and the automated extraction of dynamic signatures (i.e. resonant frequencies, mode shapes and mode complexity [13-14]). Since the dynamic response of the church is continuously collected in a well distributed measurement grid ( 27 channels of data), the features representative of structural condition should include the mode shapes and not only the resonant frequencies. The use of mode shapes and mode complexity within a SHM strategy conceivably exhibit advantages because those modal parameters might be less sensitive than resonant frequencies to exogenous factors and contain information also on the local structural behavior.

In more detail, the paper starts with a concise historic background of the Milan Cathedral and a brief description of the dynamic monitoring hardware and of the software tools developed to process the continuously acquired time series. Subsequently, the dynamic reference characteristics of the cathedral, that were identified in the first hours of dynamic monitoring, are presented and discussed. At last, the evolution in time of the environmental and modal parameters during the first year of monitoring is addressed and comments are given within a SHM perspective. 
(a)

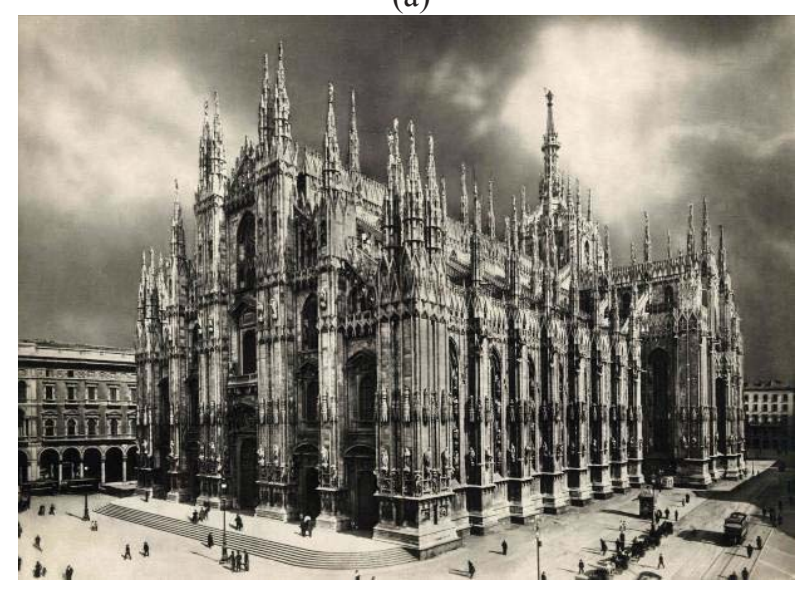

(b)

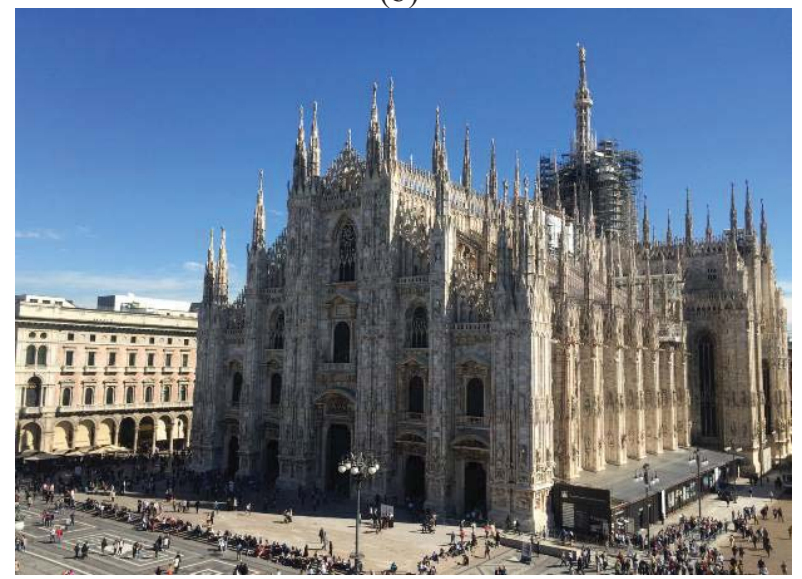

Figure 1: Past (a) and present (b) view of the Milan Cathedral (courtesy of Veneranda Fabbrica del Duomo di Milano).

(a)

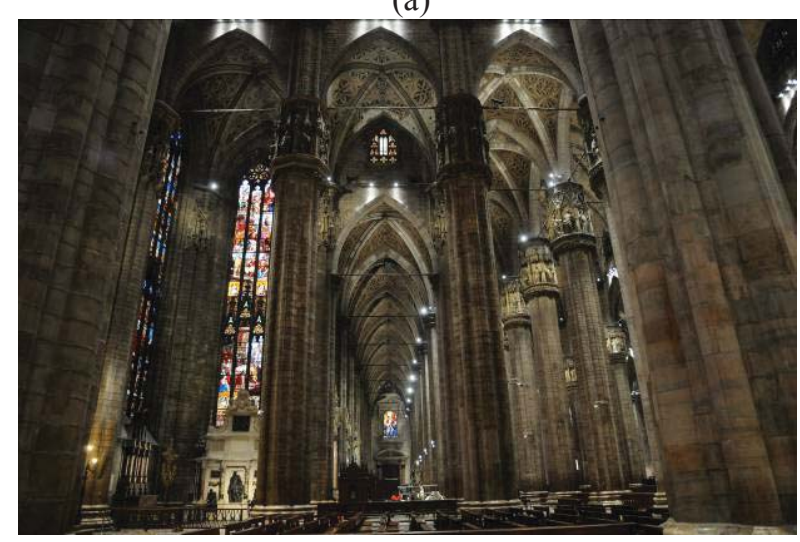

(b)

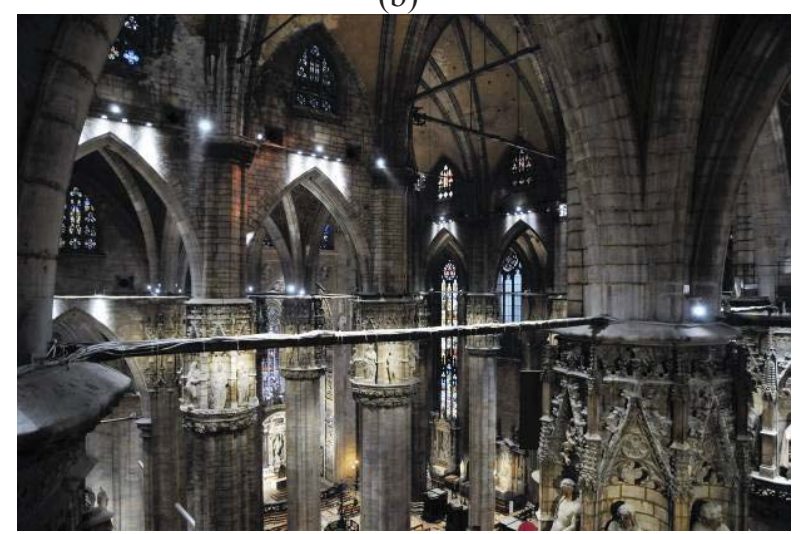

Figure 2: Inner views of piers, arches, vaults and iron tie-rods.

\section{THE MILAN CATHEDRAL}

The Milan Cathedral (Figs. 1-3) is the most representative landmark of the city of Milan and one of the largest masonry monuments ever built: the building spreads over an area of more than $10400 \mathrm{~m}^{2}$, with a volume of about $300000 \mathrm{~m}^{3}$, so that it is the second largest gothic cathedral in the world by volume and area.

The church exhibits a unique style of architecture, which is characterized by a fusion of European Gothic style and Lombardy tradition, also with the presence of neo-classic, neogothic and even renaissance influences, due to the long period required by the construction works. The church construction started in 1386 from the half-octagonal apse and East choir, and proceeded with the transept, the main dome, the tiburio (i.e., the prismatic structure with octagonal base, which is built around the main dome) and the main spire; subsequently, the five-nave structure over eight bays was built and finalized, in 1813, with a neo-Gothic façade. As previously pointed out, the inauguration of the last gate (January 6h, 1965) is generally assumed as the official ending of the monument building.

When compared with other gothic cathedrals, the Milan Cathedral exhibits a peculiar structural system, with metallic tie-rods being permanently installed under each vault (Fig. 2) and designed to exert an active part in resisting the lateral thrusts [3]. Historical documents [1] testify that the tension bars in the cathedral were permanently installed on the top of the piers during the construction, to reduce the horizontal thrust on the lateral buttresses, as those 
buttresses were judged too slender by the French architect Jean Mignot. A total of 122 metallic tie-rods (Fig. 2) is nowadays present in the cathedral and most of them are the original elements dating back to the age of construction.

A longitudinal section of the Milan Cathedral is shown in Fig. 3. The overall dimensions of the Latin cross-shaped plan are about $66 \mathrm{~m} \times 158 \mathrm{~m}$ (Fig. 4), with the aisles and the central naves spanning $9.6 \mathrm{~m}$ and $19.2 \mathrm{~m}$, respectively.

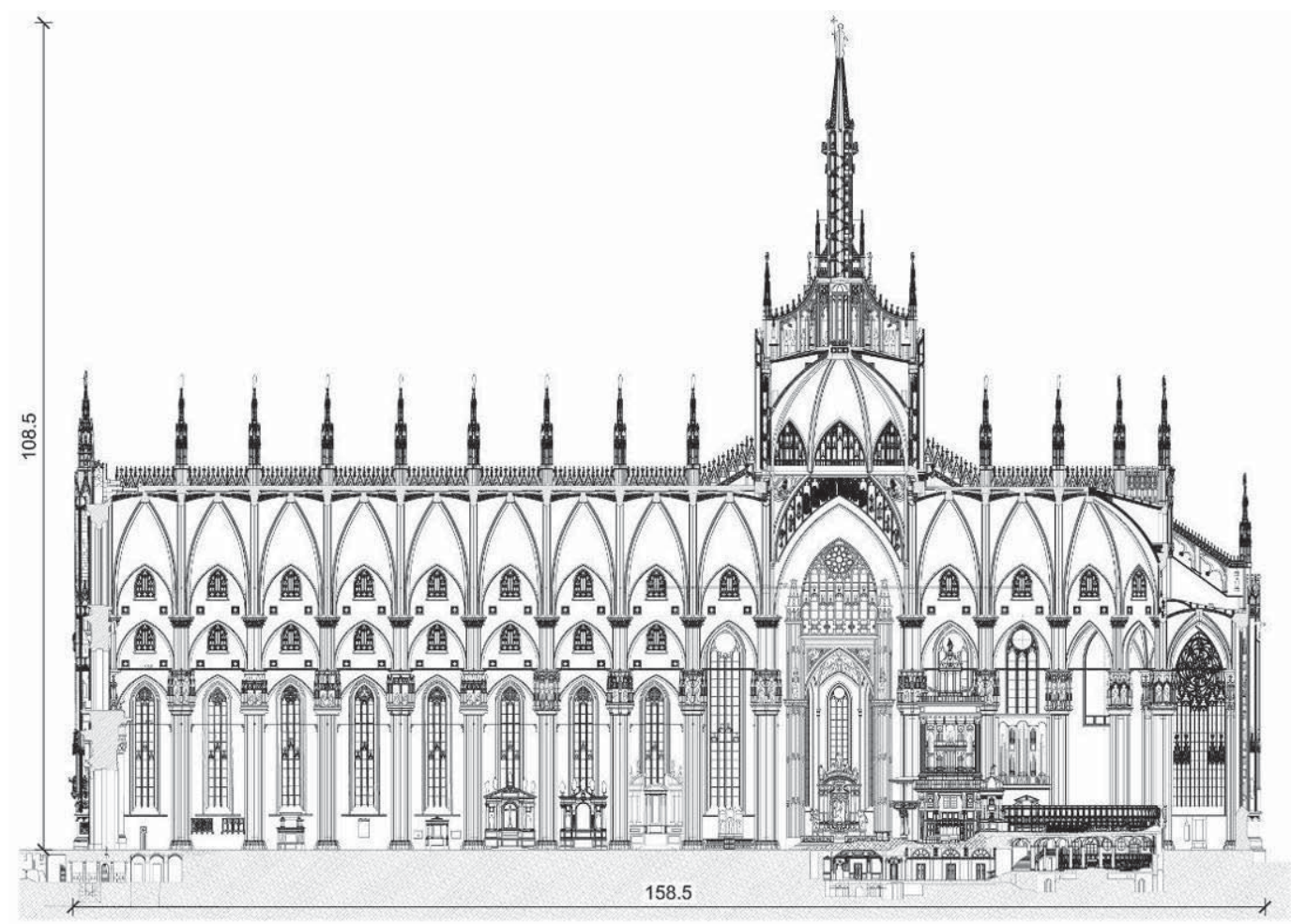

Figure 3: Longitudinal section of the Milan Cathedral (dimensions in m, courtesy of Veneranda Fabbrica del Duomo di Milano).

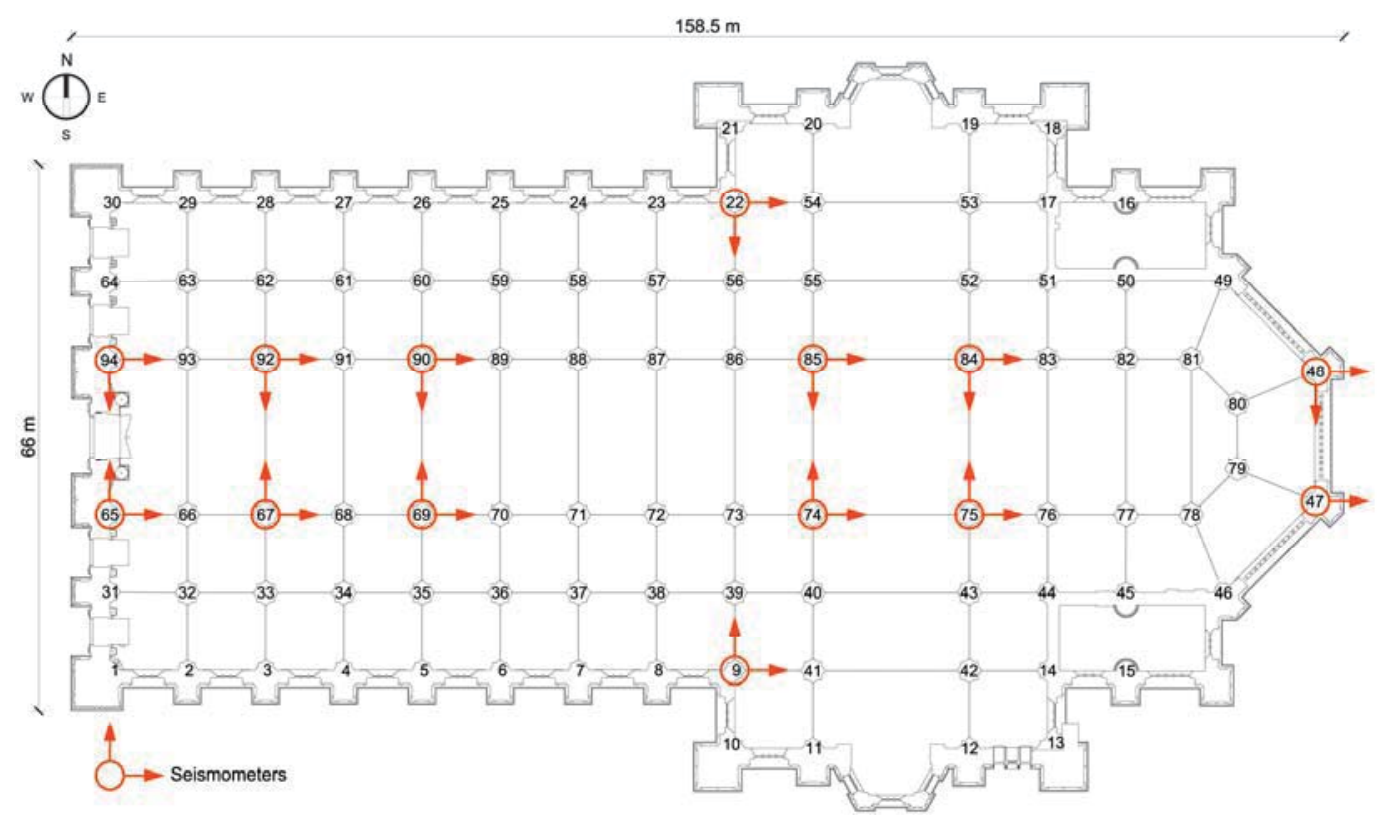

Figure 4: Plan of the Milan Cathedral (dimensions in $\mathrm{m}$ ) and layout of the seismometers installed in the church. 


\section{DYNAMIC MONITORING SYSTEM AND DATA ANALYSIS}

In order to characterize the health state of the Milan Cathedral and to address its conditionbased structural maintenance, the following key parameters are continuously measured or identified from the measurements:

- Bi-axial tilt of the capital of selected piers (i.e., piers 31, 64, 69, 90, 11, 20, 74-75, 84-85 and 47-48 in Fig. 4) and main spire;

- Strain of tie-rods 28-62, 27-61, 26-60, 35-69, 25-59, 7-37, 9-39, 39-40, 56-55, 45-77, 3872 and 87-57 (Fig. 4);

- Indoor and outdoor environmental parameters. The indoor temperature is measured in the same capitals where the tilts are recorded, whereas the humidity is measured in the neighborhood of instrumented ties. The outdoor parameters are collected through a weather station installed in the main spire;

- Resonant frequencies, mode shapes and damping ratios.

Due to the different technical characteristics of the various sensing devices and sampling rates of the data acquisition, two separated long-term monitoring systems, one static and one dynamic, were installed in the church. Strains, tilts and environmental data are collected at a rate of two samples per hour, whereas the dynamic monitoring is performed with a sampling frequency of $100 \mathrm{~Hz}$. It is further noticed that the monitoring systems are fully computer based and their architecture has been established in order to minimize wiring, as well as the visual impact of the sensing devices inside the church.

The dynamic monitoring system is based on SARA SS45 seismometers (electro-dynamic velocity transducers). Since the electro-dynamic sensors are characterized by high sensitivity of $78 \mathrm{~V} /(\mathrm{m} / \mathrm{s})$, un-necessity of powering and excellent performance in the low frequency range $(f \leq 100 \mathrm{~Hz})$, those transducers turn out to be especially suitable for the application in vibration testing or monitoring of civil engineering and cultural heritage [10] structures. The dynamic monitoring system consists of:

- 13 bi-axial seismometers and 1 mono-axial seismometer, installed at the top of selected piers inside the Cathedral (Fig. 4) and measuring the velocity in the two orthogonal N-S (transversal) and E-W (longitudinal) directions. The sensors installed on piers $(94,92$, $90),(65,67,69),(22,85,84),(9,74,75)$ and $(47,48)$ are grouped and wired to five $24-$ bit digitizers SARA SL06. Each digitizer is equipped with A/D conversion system, 8 GB memory, synchronization by GPS, back-up battery and UMTS modem for data transfer;

- $3 \times 3$ mono-axial seismometers, installed at the same levels of the main spire hosting the biaxial tilt-meters belonging to the static monitoring. The three sensors installed at each level are wired to 24-bit digitizer, with the digitizers being connected to a switch for data transfer.

The velocity data are transferred in real time to the Fabbrica workstation and stored in separate files (in compressed mini-seed format) of 1 hour. Every hour, the automatic signal processing involves the following tasks: (a) pre-processing the raw data (to compensate the low-frequency attenuation of the sensor) using the SEISMOWIN commercial software (https://www.sara.pg.it/?lang=en) and subsequent saving of the time series in text format; (b) data analysis to extract the maximum and the root mean square values and creation of a file in Matlab (.mat) format; (c) low-pass filtering and down-sampling (to reduce the sampling frequency from $100 \mathrm{~Hz}$ to $20 \mathrm{~Hz}$ ), and creation of a database of files for the application of the modal identification tools; (d) automated modal estimation and tracking. 
After the automated modal parameter estimation, only the hourly evaluated features (i.e. the statistical characteristics of each dataset and the modal parameters) and a few time series corresponding to meaningful events are permanently stored in the Fabbrica archives and can be accessed through graphical and reporting tools. It should be noticed that similar tools allow the management and visualization of the static monitoring results.

The modal parameters of the cathedral and of the main spire are independently identified using a fully automated procedure, based on the covariance-driven Stochastic Subspace Identification (SSI-Cov) algorithm [15] and developed in previous research [16]. The length of the time window adopted in the automated identification was set equal to $1 \mathrm{~h}(3600 \mathrm{~s})$. The automated procedure [16] involves the two main steps of modal parameters estimation (MPE) and modal tracking (MT).

The MPE is performed through an automatic interpretation of the stabilization diagram, based on the sensitivity of frequency and mode shape to the model order variation. For each dataset, after having filtered the spurious poles by checking the associated damping ratio and mode complexity value [13-14], the poles sharing similar frequencies and mode shapes are clustered together, and a set of representative modal parameters (i.e. resonant frequency, damping and mode shape) is estimated for each cluster. It is worth mentioning that the mode complexity is checked by averaging the information provided by both the Modal Phase Collinearity (MPC) [13] and Mean Phase Deviation (MPD) [13-14] through the Modal Complexity Index $\left(\mathrm{MCI}=0.5 \times\left[(1-\mathrm{MPC})+\left(\mathrm{MPD} / 45^{\circ}\right)\right]\right.$, varying between 0 and 1 , with 0 indicating a mono-phase behavior of the identified mode shape).

The MT, aimed at providing the time evolution of the parameters of each mode, is based on frequency and MAC [17] variation with respect to a pre-selected list of baseline modes. It is worth mentioning that this step is performed in an adaptive way, i.e. by updating the MAC and frequency variation threshold of each mode after a new dataset has been analyzed.

In the automated identification of the dynamic characteristics of the cathedral ( 27 channels of data, Fig. 4), the time lag parameter $i$ was set equal to 60 and the data were fitted using stochastic subspace models of order $n$ varying between 20 and 140; furthermore, in the noise modes elimination step, the maximum allowable damping ratio and MCI was set equal to $8 \%$ and 0.15 , respectively.

\section{DYNAMIC CHARACTERISTICS OF THE CATHEDRAL}

The grid of seismometers permanently installed in the cathedral allowed the identification and fairly good spatial description of a relatively large number of key vibration modes. Typical results obtained on the first day of continuous monitoring, in terms of resonant frequencies and mode shapes, are shown in Fig. 5 (where the blue color refers to modes with dominant motion in the N-S direction and the red color refers to modes with dominant deflection in the E-W direction). The inspection of Fig. 5 allows the following comments:

(a) The lower two modes, as expected, are global sway modes of the cathedral along the transverse $\left(\mathrm{N}-\mathrm{S}, f_{\mathrm{C} 1}=1.38 \mathrm{~Hz}\right.$, Fig. 5b) and longitudinal (E-W, $f_{\mathrm{C} 2}=1.69 \mathrm{~Hz}$, Fig. 5c) direction;

(b) The subsequent two modes $\left(f_{\mathrm{C} 3}=1.96 \mathrm{~Hz}\right.$, Fig. $5 \mathrm{~d}$ and $f_{\mathrm{C} 4}=2.51 \mathrm{~Hz}$, and Fig. 5e) involve dominant motion in the N-S direction and bending of the naves, with the deformed shapes being characterized by one and two changes of sign from apse to façade, respectively;

(c) The higher modes (Figs. 5f-i) are characterized by more complex mode shapes. For example, the 5th mode $\left(f_{\mathrm{C} 5}=2.65 \mathrm{~Hz}\right.$, Fig. 5f) involves out-of-phase bending of the North and South naves, whereas the 6 th mode $\left(f_{\mathrm{C} 6}=2.76 \mathrm{~Hz}\right.$, Fig. $\left.5 \mathrm{~g}\right)$ involves out-ofphase motion of the façade and apse in the E-W direction; 


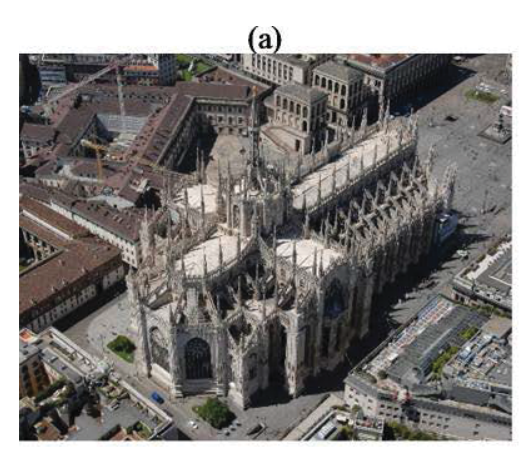

(d) $f_{\mathrm{C} 3}=1.98 \mathrm{~Hz} \quad \zeta_{\mathrm{C} 3}=2.61 \%$

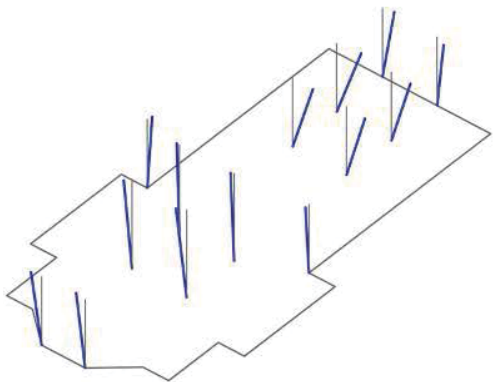

(g) $f_{\mathrm{C} 6}=2.76 \mathrm{~Hz} \quad \zeta_{\mathrm{C} 6}=5.02 \%$

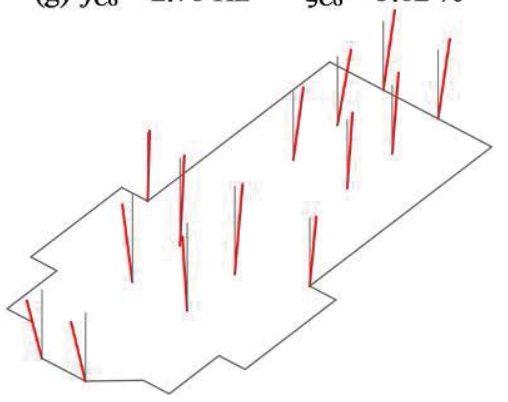

(b) $f_{\mathrm{C} 1}=1.38 \mathrm{~Hz} \quad \zeta_{\mathrm{c} 1}=4.14 \%$

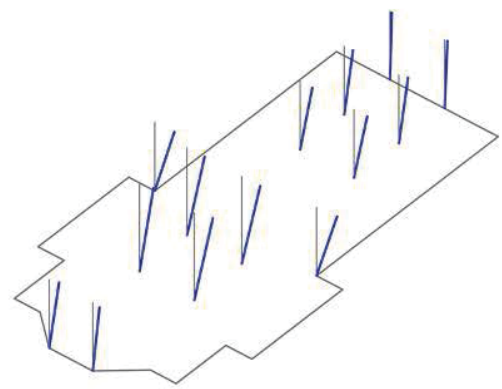

(e) $f_{\mathrm{C} 4}=2.51 \mathrm{~Hz} \quad \zeta_{\mathrm{C} 4}=3.01 \%$

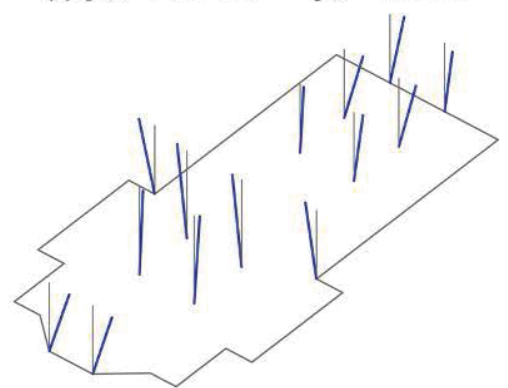

(h) $f_{\mathrm{C} 7}=3.12 \mathrm{~Hz} \quad \zeta_{\mathrm{C} 7}=2.46 \%$

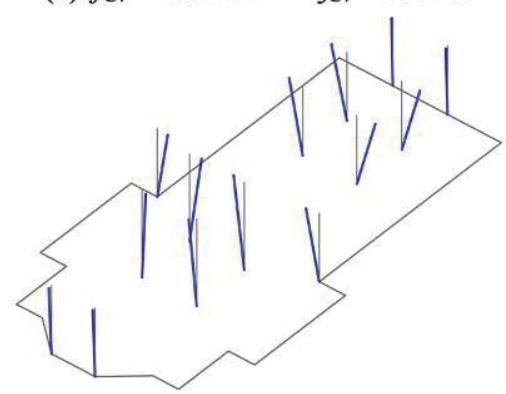

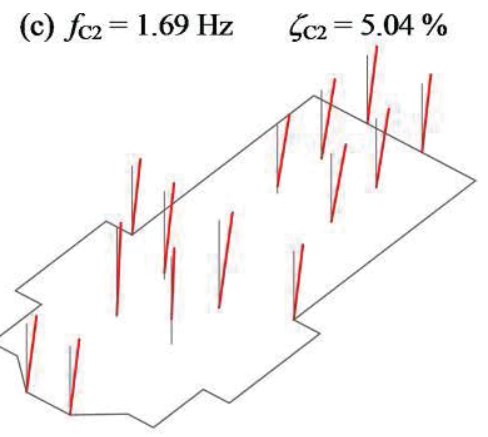

(f) $f_{\mathrm{C} 5}=2.65 \mathrm{~Hz} \quad \zeta_{\mathrm{C} 5}=1.79 \%$
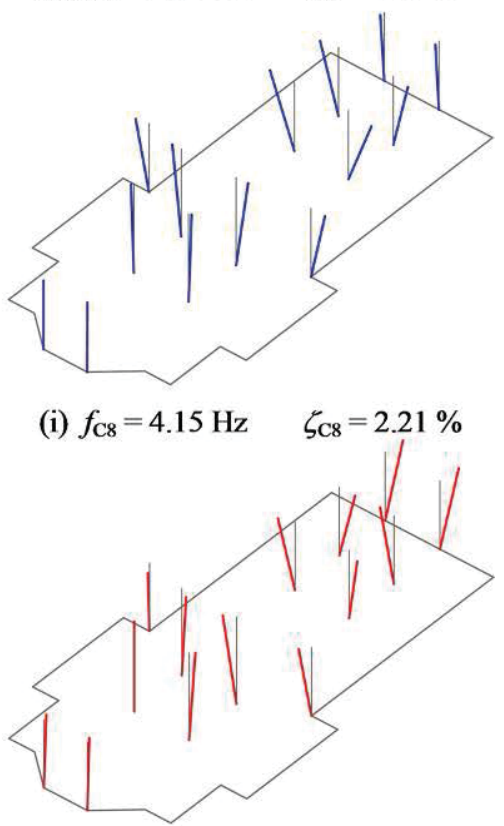

Figure 5: (a) Aerial view of the Milan Cathedral from apse and (b)-(i) identified vibration modes

(17/10/2019, h 12:00-13:00).

(d) The N-S modes exhibit damping ratios varying from $1.79 \%$ (C5) to $4.14 \%$ (C1), whereas the damping of the E-W modes ranges between $2.21 \%(\mathrm{C} 8)$ and $5.04 \%$ (C2). It is further noticed that especially the damping of E-W modes seems to be larger than generally observed at the low level of ambient excitation existing on historical buildings.

\section{SELECTED RESULTS FROM THE CONTINUOUS DYNAMIC MONITORING}

The dynamic monitoring is active in the Milan Cathedral since October 19th, 2018. This section summarizes the main results obtained during the first year of monitoring (from $16 / 10 / 2018$ to $15 / 10 / 2019$ ) and, for the sake of consistency, only the experimental results collected in the cathedral are presented and discussed (with no comments being provided on the data measured on the main spire).

As usual for masonry buildings, the evolution in time of environmental parameters is firstly presented in order to understand the effects of changing environment on the variations observed in the natural frequencies and modal parameters.

\subsection{Environmental parameters}

As previously pointed out, a quite extended grid of temperature sensors and hygrometers has been installed inside the church, to support both the SHM program and the preservation of 
the artifacts, which are kept inside the monument. The variation in time of the average indoor temperature and the outdoor temperature (measured by the weather station) is shown in Fig. $6 a$, whereas Fig. $6 \mathrm{~b}$ refers to the average indoor humidity. The orange line in Fig. 6a presents the evolution of the outdoor temperature and highlights changes between $-1.7^{\circ} \mathrm{C}$ and $+35.4^{\circ} \mathrm{C}$, with remarkable daily variations in sunny days. The corresponding variation of the average indoor temperature is represented by the red line in Fig. $6 \mathrm{a}$ and ranges between $+8.8^{\circ} \mathrm{C}$ and $+30.6^{\circ} \mathrm{C}$ : it is further noticed that the availability of a large number of temperature sensors in the church highlights [12] a low temperature gradient in space, with the difference between the extreme values not exceeding $0.5^{\circ} \mathrm{C}$. Consequently, the low temperature gradient and the correlation coefficients (always larger than 0.99) between the measured temperatures allow to assume the average indoor temperature (Fig. 6a) as a representative quantity for the SHM correlations. A similar conclusion is drawn for the relative humidity, whose time series are highly correlated $[4,12]$ and exhibit correlation coefficients of the order of 0.90 or larger.

(a)

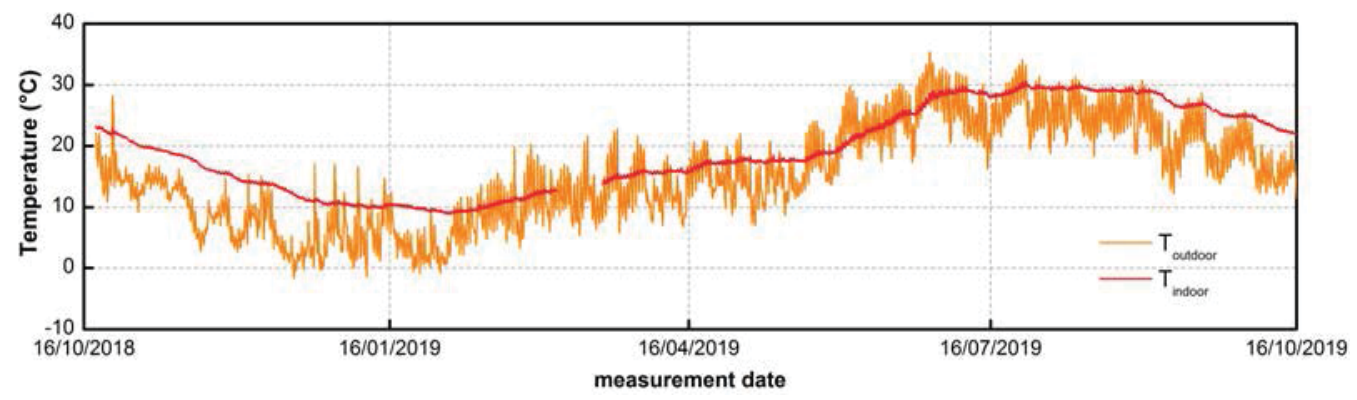

(b)

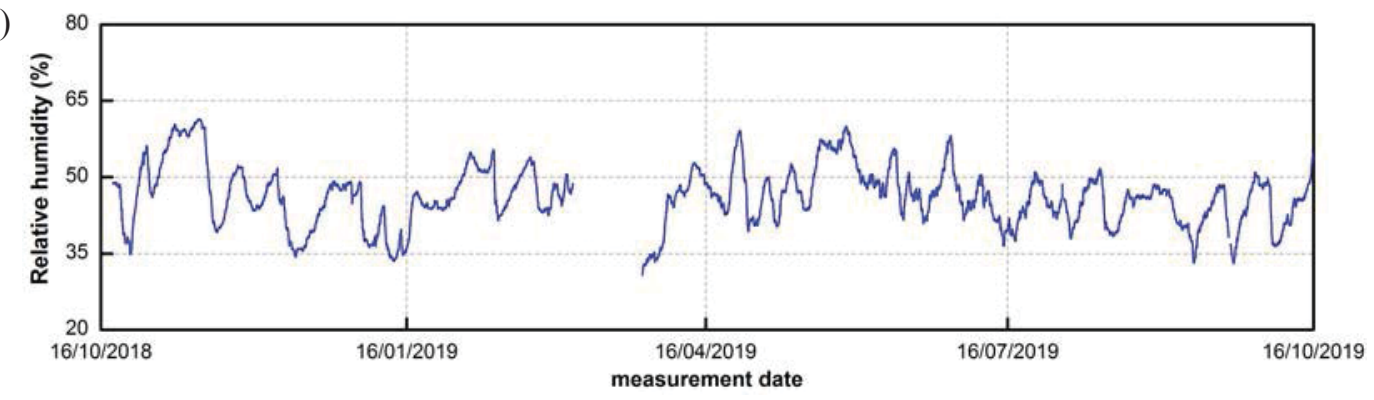

Figure 6: Evolution in time of: (a) average indoor temperature and outdoor temperature; (b) average indoor relative humidity.

\subsection{Environmental effects on natural frequencies}

The results of automated modal identification and frequency tracking during the first year of monitoring are exemplified in Fig. 7 for the lower 6 modes of the cathedral, exhibiting the higher identification rate. The complete results of automated OMA in terms of natural frequencies and damping ratios are summarized in Table 1 with some statistical information. In more details, Table 1 lists the identification rate, the mean value $\left(f_{\text {mean }}\right)$ and the standard deviation $\left(\sigma_{\mathrm{f}}\right)$ of the automatically identified frequencies and their extreme values $\left(f_{\min }, f_{\max }\right)$ as well as the mean value $\left(\zeta_{\text {mean }}\right)$ and the standard deviation $\left(\sigma_{\zeta}\right)$ of the damping ratio.

It should be noticed that the identification rate of the frequencies in Fig. 7 ranges between $99.8 \%$ and $88.9 \%$ (Table 1), whereas the higher two frequencies exhibit lower identification success ratios still allowing the tracking with an acceptable continuity.

As expected [5-11], Fig. 7 reveals clear long-term variations as well as daily fluctuations of natural frequencies, that are conceivably associated with changing temperature. In addition, the environmental effects turn out to be very distinctive and this peculiarity is understood, for 
example, by carefully inspecting the time evolution of $f_{\mathrm{C} 2}$ and $f_{\mathrm{C} 4}$ in Fig. 7. Those modes, whose variation is quite easy to inspect in Fig. 7, are characterized by dominant motion in the longitudinal $\mathrm{E}-\mathrm{W}\left(f_{\mathrm{C} 2}\right)$ and transverse N-S $\left(f_{\mathrm{C} 4}\right)$ direction (Fig. 5).

\begin{tabular}{cccccccc}
\hline Mode & Id. Rate & $f_{\text {mean }}(\mathrm{Hz})$ & $\sigma_{\mathrm{f}}(\mathrm{Hz})$ & $f_{\min }(\mathrm{Hz})$ & $f_{\max }(\mathrm{Hz})$ & $\zeta_{\text {mean }}(\%)$ & $\sigma_{\zeta}(\%)$ \\
\hline \hline C1 & $99.8 \%$ & 1.383 & 0.011 & 1.359 & 1.423 & 3.73 & 0.24 \\
C2 & $99.3 \%$ & 1.677 & 0.020 & 1.605 & 1.739 & 5.17 & 0.81 \\
C3 & $99.3 \%$ & 1.993 & 0.015 & 1.956 & 2.059 & 3.24 & 0.42 \\
C4 & $97.9 \%$ & 2.530 & 0.021 & 2.477 & 2.632 & 3.25 & 0.42 \\
C5 & $96.4 \%$ & 2.668 & 0.021 & 2.609 & 2.757 & 1.42 & 0.32 \\
C6 & $88.9 \%$ & 2.778 & 0.034 & 2.683 & 2.923 & 5.15 & 0.55 \\
C7 & $71.4 \%$ & 3.170 & 0.051 & 3.066 & 3.383 & 2.56 & 0.53 \\
C8 & $36.9 \%$ & 4.177 & 0.038 & 4.094 & 4.350 & 1.80 & 0.31 \\
\hline
\end{tabular}

Table 1: Statistics of the natural frequencies and damping ratios identified in the first year of monitoring.

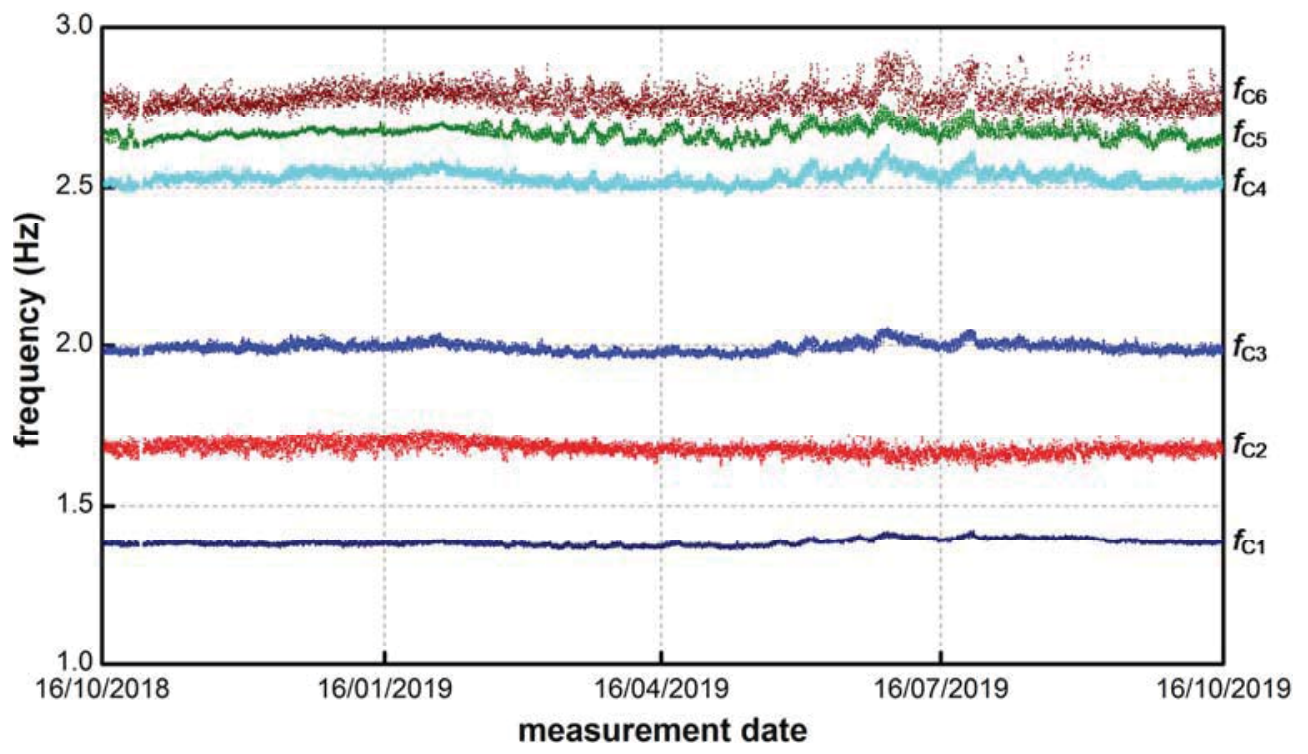

Figure 7: Variation in time of the natural frequencies of the lower 6 modes during the first year of monitoring.

Figure 7 highlights that the frequency of mode C2 clearly increases with decreased indoor and outdoor temperature (Fig. 6a) and decreases with increased temperature: this trend, which is exactly the opposite of what expected for masonry buildings [6-11], is confirmed by plotting the frequency $f_{\mathrm{C} 2}$ versus the outdoor temperature (Fig. 8a), along with the best fit line: even if for a given temperature a quite remarkable frequency variation is observed, negative temperature correlation is exhibited by frequency $f_{\mathrm{C} 2}$ during the entire monitoring period. It is worth mentioning that: (a) a negative frequency-temperature correlation is obtained with indoor average temperature and (b) the temperature effect on $\mathrm{E}-\mathrm{W}$ mode $f_{\mathrm{C} 6}$ is remarkably similar to what observed for mode $f_{\mathrm{C} 2}$, especially in the cold season (Fig. 7).

Even more complicated temperature-driven mechanisms characterize the variation of N-S modes: as shown in Fig. 7, the frequency $f_{\mathrm{C} 4}$ tends to increase both in the cold and in the hot season and a similar trend is exhibited by N-S modes $f_{\mathrm{C} 1}, f_{\mathrm{C} 3}$ and $f_{\mathrm{C} 5}$. The correlation between $f_{\mathrm{C} 4}$ and the outdoor temperature is exemplified in Fig. $8 \mathrm{~b}$ and, as it has to be expected, a non linear best fit line is obtained. 
(a)



(b)

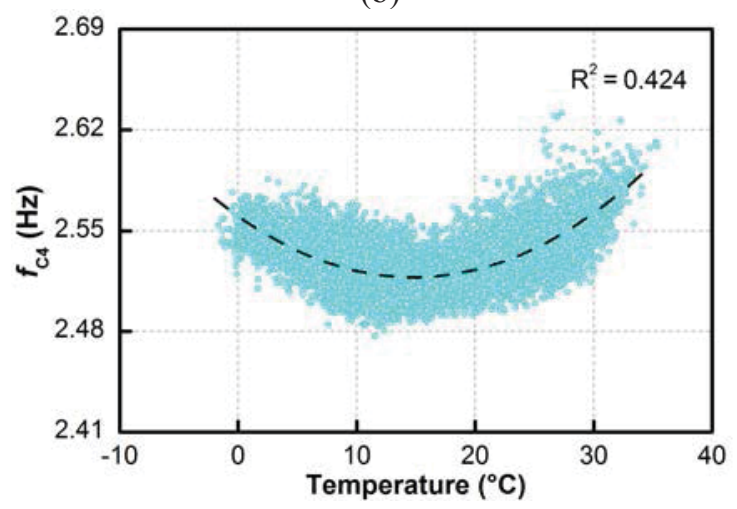

Figure 8: Correlation between outdoor temperature and identified natural frequencies: (a) $f_{\mathrm{C} 2}$ and (b) $f_{\mathrm{C} 4}$.

It is further noticed that, during the cold season, a generalized (tensile) strain increase with decreased temperature is measured by the extensometers installed in the tie-rods [4]. Hence, the corresponding increased forces in the tension bars conceivably exert a stiffening action on the overall structure since the metallic tie-rods form a grid of stiffening elements spread over the entire cathedral (Fig. 2).

In summary, all natural frequencies of the cathedral exhibit a negative dependence on both indoor and outdoor temperatures in the cold season, whereas the correlation changes in the hot season, for the $\mathrm{N}-\mathrm{S}$ modes only. The negative dependence of natural frequencies on temperature is a distinctive behavior of the Milan Cathedral, with this trend being very different from what generally reported in the long-term studies on masonry structures, either towers $[6,7,10]$ or churches $[6,8-9]$. Indeed, a negative frequency-temperature correlation is only reported in the literature for a monumental building [11], which is characterized by the presence of metallic tie-rods, as well.

In the authors' opinion, the complex dependence of natural frequencies on temperature observed in the Milan Cathedral results from two temperature-driven opponent effects: the stiffening exerted during the cold season by the increased tensile forces in the metallic grid of tie-rods and the usual thermal expansion of the masonry materials. The former effect turns out to be dominant in the cold season for all modes, whereas the latter tends to overcome in the hot season, for N-S modes.

Notwithstanding the complex temperature-driven behavior of the cathedral and the difference of trend exhibited by N-S and E-W modes, the removal of environmental effects can be performed, for example, by applying the principal component analysis (PCA) [18] to the frequency data collected during an appropriate training period. In the present application, the lower 6 modes (Fig. 7) were considered and the training period includes the first year of monitoring.

Since two latent sources of temperature-driven variability have been suggested by the previous analysis and those sources affect differently the N-S and E-W modes, the first four PCs are retained in order to establish the PCA-based model. As shown in Fig. 9, the PCA provides a very effective removal of the environmental effects.

Once the PCA-based prediction model has been established using the data collected during an appropriate training period, the occurrence of abnormal structural changes not observed during the training period is often detected by using the residual errors (i.e., the difference between the identified frequency and its prediction). Anomaly detection approaches might involve: (a) verifying that each prediction error does not exceed 95\% confidence interval [19] or (b) using the prediction errors within the framework of statistical control charts (such as the well-known Hotelling's $T^{2}$ control chart [20]). 


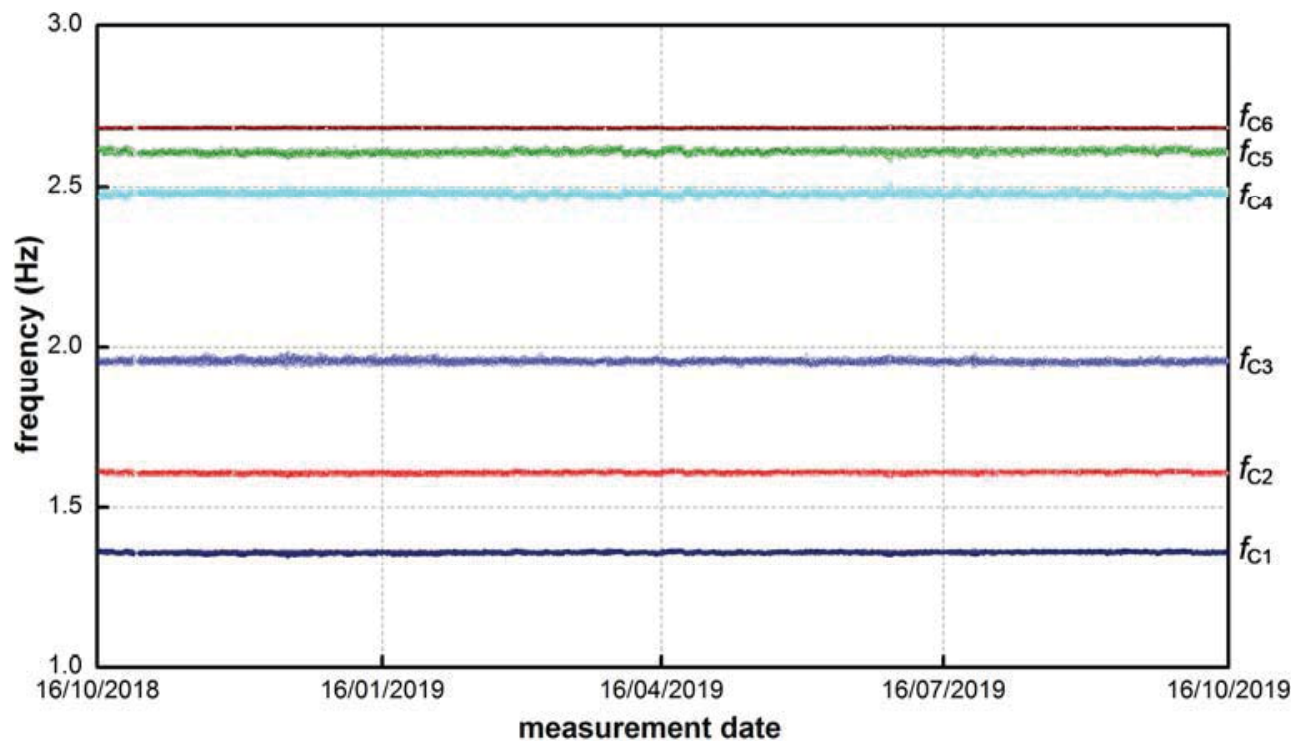

Figure 9: Variation in time of the natural frequencies of the lower 6 modes during the first year of monitoring, after the PCA-based removal of the environmental effects.
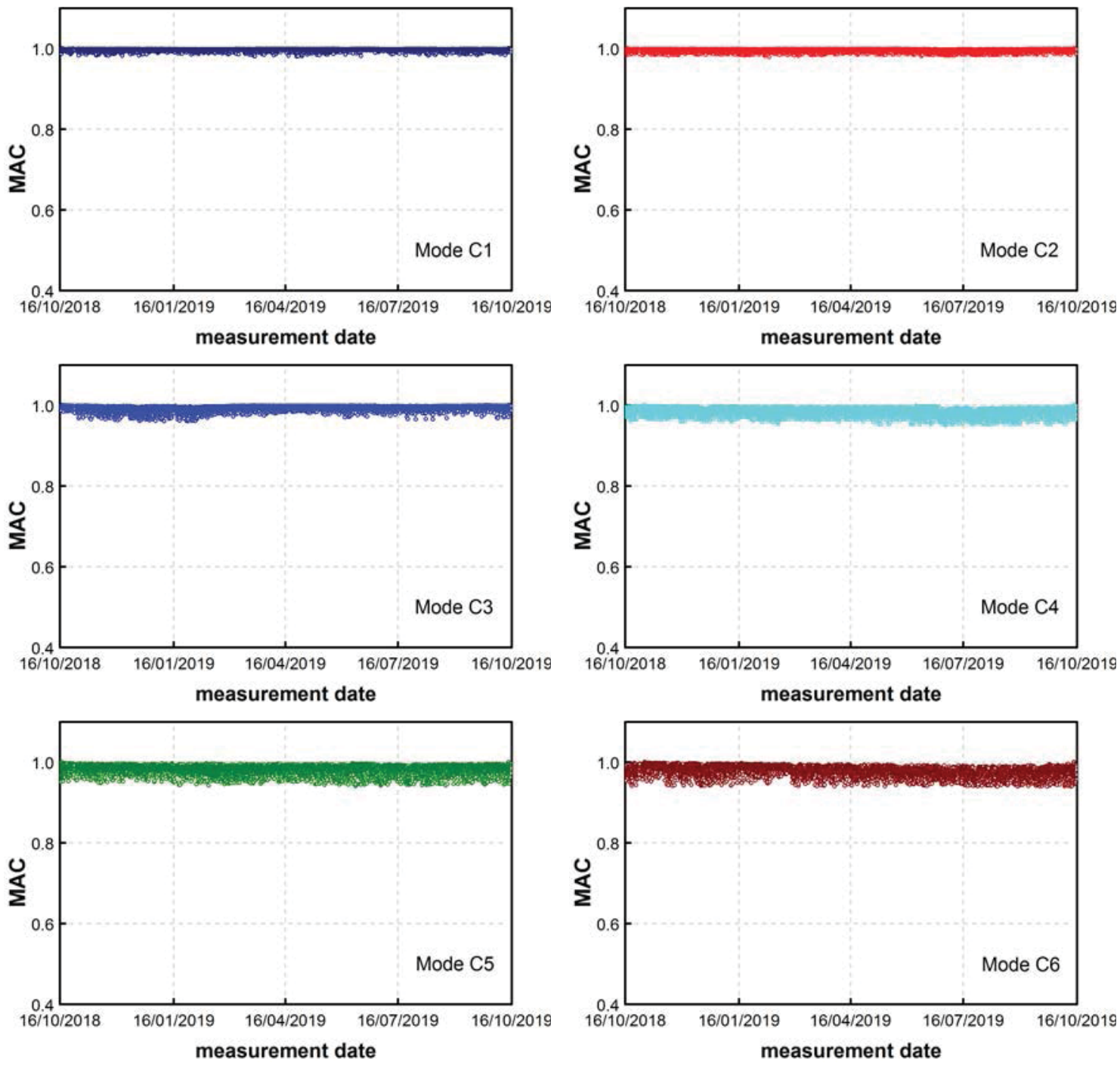

Figure 10: Variation in time of the MAC of the lower 6 modes during the first year of monitoring. 


\begin{tabular}{ccccccc}
\hline Mode & $M A C_{\text {mean }}$ & $\sigma_{\mathrm{MAC}}$ & $M A C_{\text {min }}$ & $M P C_{\text {mean }}$ & $\sigma_{\mathrm{MPC}}$ & $M P C_{\min }$ \\
\hline \hline C1 & 0.997 & 0.002 & 0.980 & 0.993 & 0.003 & 0.978 \\
C2 & 0.995 & 0.003 & 0.979 & 0.992 & 0.004 & 0.968 \\
C3 & 0.993 & 0.006 & 0.960 & 0.988 & 0.010 & 0.932 \\
C4 & 0.984 & 0.008 & 0.950 & 0.949 & 0.024 & 0.880 \\
C5 & 0.981 & 0.011 & 0.941 & 0.980 & 0.017 & 0.912 \\
C6 & 0.978 & 0.012 & 0.939 & 0.928 & 0.024 & 0.861 \\
C7 & 0.968 & 0.020 & 0.911 & 0.934 & 0.028 & 0.852 \\
C8 & 0.950 & 0.019 & 0.900 & 0.911 & 0.033 & 0.821 \\
\hline
\end{tabular}

Table 1: Statistics of MAC and MPC of modes identified in the first year of monitoring.

\subsection{Mode shapes and mode complexity}

As previously pointed out, a quite dense network of high quality seismometers is installed in the Milan Cathedral, so that the mode shape variations should be investigated with SHM purposes. Since the environmental changes affect almost uniformly any structural system, the mode shapes are supposed to be less sensitive [10] than natural frequencies to those changes. Consequently, if the mode shapes turn out to be approximately time-invariant during an appropriate observation period (including a statistically representative sample of environmental conditions), any subsequent variation in the mode shapes conceivably provides the evidence of a structural change [21]. On the other hand, even if mode shapes contain also local information on the structure, those parameters might exhibit low sensitivity to local structural changes.

The evolution during the first year of monitoring of the mode shape variation, in terms of MAC, is shown in Fig. 10 for the lower 6 modes. It should be noticed that the MAC index is computed between a pre-selected set of reference mode shapes (corresponding to the same set of baseline modes used in the automated procedure of modal identification, Fig. 5) and the currently identified mode shapes. Figure 10 highlights that the MAC values (i.e., the mode shapes) are approximately independent of temperature and time invariant, even if the standard deviation of the MAC tends to increase with the increasing mode order (i.e., with the increasing spatial complexity of the distribution of modal deformations, Fig. 5). Columns 2-4 of Table 2 summarize the statistical characteristics of the MAC in terms of average value $\left(\mathrm{MAC}_{\text {mean }}\right)$, standard deviation $\left(\sigma_{\mathrm{MAC}}\right)$ and minimum value $\left(\mathrm{MAC}_{\mathrm{min}}\right)$.

The investigation on mode shape changes was carried out also by considering the mode complexity, through the MPC (i.e., the collinearity of the mode shape components of each single mode on a straight line in the complex plane). Figure 11 and columns 5-7 of Table 2 demonstrate that also the MPC measure of mode complexity [13] is approximately time invariant, even if the MPC values tend to depart from unity (perfect collinearity) and to exhibit an increased dispersion for the higher modes.

\section{CONCLUSIONS}

The paper focuses on the monitoring program of the Milan Cathedral. Special emphasis is given on the dynamic measurements, the automated extraction of modal signatures and the influence of environmental changes on the variations observed in the dynamic characteristics of the historic monument. Based on the results collected in the first year of monitoring (i.e., between 16/10/2018 and 15/104/2019), the following main conclusions can be drawn:

- The application of state-of-art tools for automated operational modal analysis allows accurate estimate and tracking of 8 resonant frequencies in the frequency interval 0-5 Hz. 

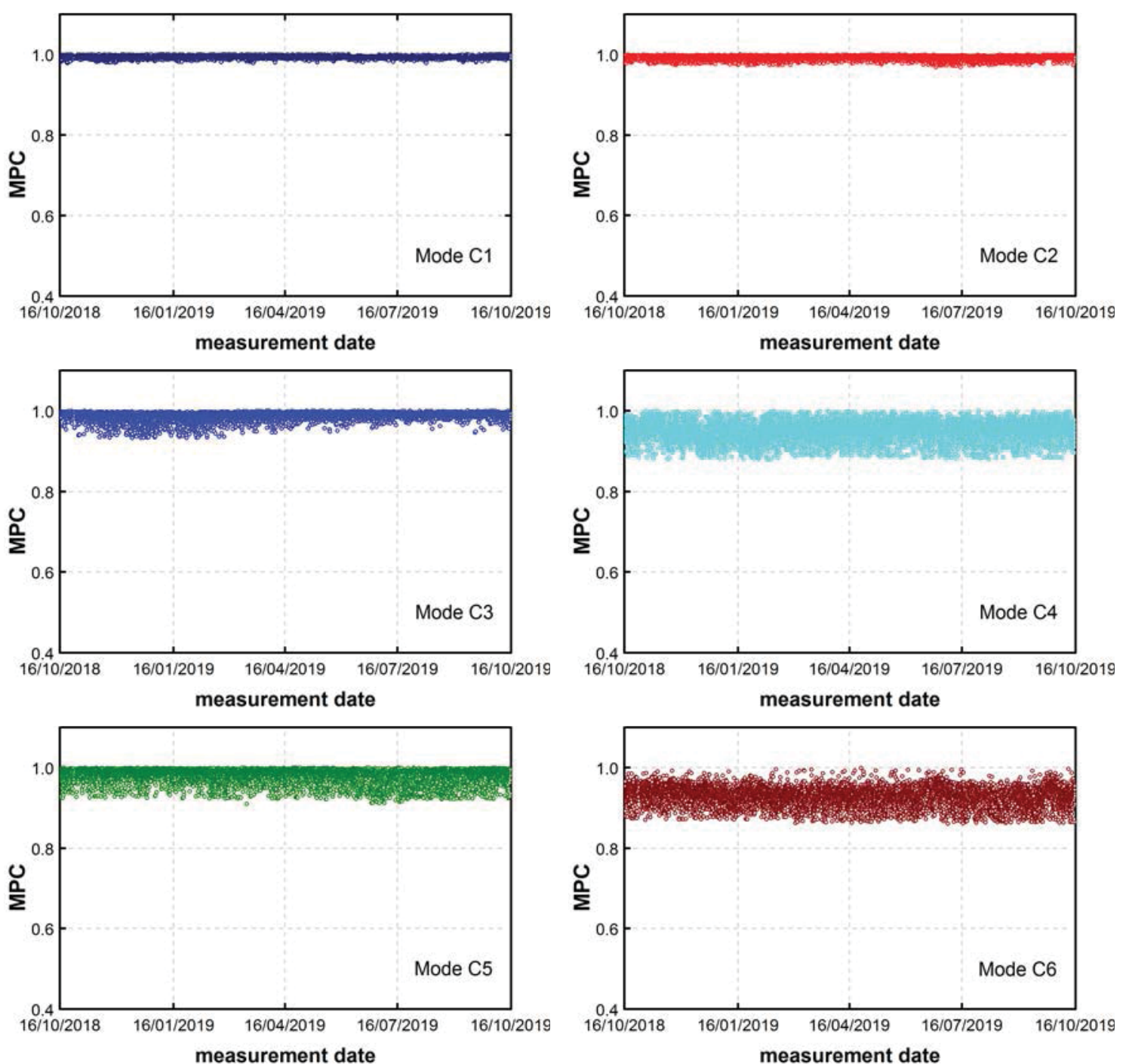

Figure 11: Variation in time of the MPC of the lower 6 modes during the first year of monitoring.

- The automatically identified modes involve dominant motion in the main transverse $(\mathrm{N}-\mathrm{S})$ and longitudinal (E-W) direction of the cathedral.

- The (outdoor and indoor) temperature turned out to be a dominant driver of the variations observed in the fluctuation of the resonant frequencies of all modes. The relative humidity seems to slightly affect only the frequency of the first mode [4].

- The frequency-temperature correlations reveal a distinctive trend, which is very different from what reported in almost all long-term studies on historic masonry structures. The natural frequencies of the cathedral exhibit a negative dependence on indoor and outdoor temperature in the cold season, whereas the correlation becomes positive in the hot season, for the N-S modes only.

- The complex dependence of natural frequencies on temperature observed in the Milan Cathedral conceivably results from two temperature-driven opponent effects: the stiffening exerted during the cold season by the increased tensile forces in the metallic tie-rods and the usual thermal expansion of the masonry materials. The former effect turns out to be dominant in the cold season for all modes, whereas the latter tends to rule the frequency variation of N-S modes in the hot season. 
- PCA-based regression models are suitable to remove the environmental effects from natural frequencies.

- The mode shapes of the cathedral and the corresponding mode complexity (evaluated via MPC) do not exhibit appreciable fluctuations associated with the environmental effects, so that an appropriate strategy of SHM should be based also on the time invariance of modal deformations.

\section{ACKNOWLEDGEMENTS}

The support of Veneranda Fabbrica del Duomo di Milano and the precious co-operation of Francesco Canali is gratefully acknowledged. The authors would like to thank the technical staff of AGISCO and Veneranda Fabbrica del Duomo di Milano for mounting all monitoring devices, and the technical staff of SARA Electronics Instruments for the assistance during the installation and the initial operational setting of the seismometers.

\section{REFERENCES}

[1] Annali della Fabbrica del Duomo di Milano. Dall'origine fino al presente (in Italian), Veneranda Fabbrica del Duomo di Milano, 1885.

[2] C. Ferrari da Passano, Storia della Veneranda Fabbrica (in Italian), Cassa di Risparmio delle Province Lombarde, 1973.

[3] C. Gentile, C. Poggi, A. Ruccolo, M. Vasic, Vibration-based assessment of the tensile force in the tie-rods of the Milan Cathedral, International Journal of Architectural Heritage 13(3), 402-415, 2019.

[4] C. Gentile, A. Ruccolo, F. Canali, Long-term monitoring for the condition-based structural maintenance of the Milan Cathedral, Construction and Building Materials 228, 117101, 2019.

[5] H. Sohn, Effects of environmental and operational variability on structural health monitoring, Philosophical Transactions of the Royal Society A 365, 539-560, 2007.

[6] L.F. Ramos, L. Marques, P.B. Lourenço, G. De Roeck, A. Campos-Costa, J. Roque, Monitoring historical masonry structures with operational modal analysis: two case studies, Mechanical Systems and Signal Processing 24(5), 1291-1305, 2010.

[7] A. Saisi, C. Gentile, M. Guidobaldi, Post-earthquake continuous dynamic monitoring of the Gabbia Tower in Mantua, Italy, Construction and Building Materials 81, 101-112, 2015 .

[8] M.G. Masciotta, J.C.A. Roque, L.F. Ramos, P.B. Lourenço, A multidisciplinary approach to assess the health state of heritage structures: the case study of the Church of Monastery of Jerónimos in Lisbon, Construction and Building Materials 116, 169-187, 2016.

[9] A. Elyamani, O. Caselles, P. Roca, J. Clapes, Dynamic investigation of a large historical cathedral, Structural Control and Health Monitoring 24(3), e1885, 2017.

[10] R.M. Azzara, G. De Roeck, M. Girardi, C. Padovani, D. Pellegrini, E. Reynders, The 
influence of environmental parameters on the dynamic behaviour of the San Frediano bell tower in Lucca, Engineering Structures 156, 175-187, 2018.

[11] A. Kita, N. Cavalagli, F. Ubertini, Temperature effects on static and dynamic behavior of Consoli Palace in Gubbio, Italy, Mechanical Systems and Signal Processing 120, 180-202, 2019.

[12] N. Aste, R.S. Adhikari, M. Buzzetti, S. Della Torre, C. Del Pero, H.E. Huerto, C.F. Leonforte, Microclimatic monitoring of the Duomo (Milan Cathedral): risks-based analysis for the conservation of its cultural heritage, Building Environment 148, 240$257,2019$.

[13] R.S. Pappa, K.B. Elliott, A. Schenk, A Consistent-mode indicator for the eigensystem realization algorithm, NASA Technical Memorandum 107607, 1992.

[14] [26] W. Heylen, S. Lammens, P. Sas, Modal Analysis: Theory and Testing, KU Leuven, Belgium, 2007.

[15] B. Peeters, G. De Roeck, Reference-based stochastic subspace identification for outputonly modal analysis, Mechanical Systems and Signal Processing 13(6), 855-878, 1999.

[16] A. Cabboi, F. Magalhães, C. Gentile, À. Cunha, Automated modal identification and tracking: application to an iron arch bridge, Structural Control Health Monitoring 24(1), e1854, 2017.

[17] R.J. Allemang, D.L. Brown, A correlation coefficient for modal vector analysis, Proceedings of the 1st International Modal Analysis Conference (IMAC-I), 1982.

[18] S. Sharma, Applied Multivariate Techniques, John Wiley \& Sons, 1995.

[19] Peeters B, De Roeck G. One-year monitoring of the Z24-Bridge: environmental effects versus gamage events. Earthquake Engineering \& Structural Dynamics 30, 149-171, 2001.

[20] H. Hotteling, Multivariate quality control, illustrated by the air testing of sample bombsights, Techniques of Statistical Analysis, 111-184, 1947.

[21] A. Cabboi, C. Gentile, A. Saisi, Vibration-based SHM of a centenary bridge: a comparative study between two different automated OMA techniques, Proceedings of the 9th International Conference on Structural Dynamics, 2014. 